\title{
Um grão de sal: autenticidade, felicidade e relações de amizade na correspondência de Mário de Andrade com Carlos Drummond ${ }^{*}$
}

\author{
A Grain of Salt: Authenticity, Happiness and Friendship in Mário de \\ Andrade's Correspondence with Carlos Drummond
}

\author{
Ricardo Benzaquen de Araújo \\ rbenzaquen@puc-rio.br \\ Professor Titular \\ Pontifícia Universidade Católica do Rio de Janeiro \\ Rua Marquês de São Vicente, 225, F512 - Gávea \\ 22451900 - Rio de Janeiro - RJ \\ Brasil
}

\begin{abstract}
Resumo
O texto em pauta pretende examinar a forma pela qual Mário de Andrade elabora a sua subjetividade na correspondência que troca com Carlos Drummond de Andrade. O seu argumento central é o de que a personalidade sanguínea, forte e autêntica de Mário não desconhece momentos de insegurança, abandono e até desilusão, momentos que, paradoxalmente, só conseguem ser superados pelo recurso a experiências marcadas pela dor física e espiritual a que ele, nas próprias relações de amizade - em função, por exemplo, das críticas que the são endereçadas pelos amigos -, não deixa de se submeter. Assim, longe de procurar a felicidade em um terreno utópico, no futuro ou no além, nosso autor se arrisca a confrontar diretamente o infortúnio, convicto de que os desafios e a alteridade embutidos nesse gesto serão capazes de gerar uma energia em condições de aperfeiçoar a sua intensa, fecunda e quase excessiva identidade pessoal.
\end{abstract}

\section{Palavras-chave}

Mário de Andrade; Modernismo; Subjetividade.

\begin{abstract}
The present paper examines the way Mario de Andrade fashions his subjectivity in his correspondence with Carlos Drummond de Andrade. The central argument is that Mario de Andrade's passionate, strong and authentic personality is not unfamiliar with moments of insecurity, dejection and even disillusionment. Paradoxically, those moments can only be overcame by experiences of physical and spiritual pain, to which he subjects himself in his own friendship relations - for instance, through criticisms addressed to him by his friends. Thus, far from seeking happiness in a utopic ground, in the future or in the after-life, the author risks openly confronting misfortune, in the assurance that the challenges and the otherness built into this gesture will be in conditions to generate an energy capable of improving his intense, fertile and almost excessive personality.
\end{abstract}

\section{Keywords}

Mário de Andrade; Modernism; Subjectivity.

Recebido em: 29/8/2014

Aprovado em: 7/10/2014

\footnotetext{
* Quero agradecer o auxílio que me foi prestado por João Duarte, bolsista de PNPD junto à pós-graduação em História Social da Cultura da PUC-Rio, na formatação do texto para a publicação. Sou também muito grato aos amigos e colegas Sergio Miceli (USP) e Jorge Myers (Quilmes), que me convidaram a escrever uma primeira versão deste texto a ser publicada em espanhol, numa coletânea sobre história dos intelectuais da América Latina, daqui a certo tempo.
} 
O principal objetivo deste trabalho é analisar a forma por intermédio da qual Mário de Andrade elabora a sua subjetividade na correspondência trocada com Carlos Drummond de Andrade - Carlos e Mário: Correspondência entre Carlos Drummond de Andrade - inédita - e Mário de Andrade: 1924-1945 (2002). Não se trata, é necessário esclarecer desde logo, de tarefa das mais fáceis, não só porque não sou um especialista na obra de Mário, mas também porque o próprio material investigado parece mostrar-se particularmente resistente à interpretação: submetidas a uma permanente oscilação, as cartas dão a impressão de registrar com enorme plasticidade e minúcia - como se fossem feitas de cera - as menores alterações de humor do nosso autor, abrindo um leque decorado com tanta riqueza, colorido e variedade que o seu exame ameaça se converter em uma empreitada das mais arriscadas. ${ }^{1}$

Essa, aliás, foi uma das razões - embora não a decisiva - que fizeram com que o texto que se segue viesse a concentrar as suas atenções no estudo do primeiro ano daquela correspondência, entre outubro de 1924 e fins de 1925, iniciada logo depois da passagem de Mário por Belo Horizonte em seu retorno a São Paulo junto com a comitiva modernista que havia visitado Ouro Preto: Oswald de Andrade, Tarsila do Amaral e Blaise Cendrars, entre outros. As cartas aí compreendidas situam-se, sem dúvida, entre as mais instigantes do "corpus" em pauta, mas é evidente que a possibilidade de circunscrever a discussão, levando-se em conta os limites fixados para este artigo, pode ser de grande valia na busca de um entendimento mais complexo e matizado do modo pelo qual Mário procura modelar a sua identidade no diálogo com Drummond.

Pois bem: passando agora para a consideração de questões mais substantivas, creio que seja possível levantar uma primeira hipótese que sugere que Mário possa ser definido como portador de uma personalidade forte, totalmente incapaz, portanto, de respeitar as fronteiras que, impostas à correspondência desde o começo da época moderna, confinavam-na a um circuito balizado pelas regras da conveniência e do decoro, terminando por conformar uma espécie de retórica epistolar. ${ }^{2}$

Basta comparar, por exemplo, a abertura da primeira carta de Drummond, datada de 28 de outubro de 1924, com as linhas iniciais da resposta que lhe é enviada por Mário em 10 de novembro do mesmo ano:

Prezado Mário de Andrade,

Procure-me nas suas memórias de Belo Horizonte: um rapaz magro, que esteve consigo no Grande Hotel, e que muito o estima. Ora, eu desejo prolongar aquela fugitiva hora de convívio com seu claro espírito. Para isso utilizo-me de um recurso indecente: mando-lhe um artigo meu que você lerá em dez minutos (FROTA 2002, p. 40).

Em contrapartida, lemos o seguinte:

Meu caro Carlos Drummond

\footnotetext{
${ }^{1}$ Empreitada que só não se torna ainda mais difícil porque já contamos com o trabalho de Moraes (2007) sobre a epistolografia de Mário de Andrade.

2 Sobre esta questão, vale a pena uma consulta à coletânea organizada por Chartier (1991).
} 
Já começava a desesperar da minha resposta? Meu Deus! comecei esta carta com pretensão... Em todo caso de mim não desespere nunca. Eu respondo sempre aos amigos. Às vezes demoro um pouco, mas nunca por desleixo ou esquecimento. As solicitações da vida é que são muitas e as da minha agora muitíssimas e... Quer saber quais são? (FROTA 2002, p. 46).

Assim, se Drummond transmite a sensação de preservar aquelas normas de conveniência e decoro, recorrendo a uma estudada modéstia para se apresentar diante de um interlocutor que mal conhece, mais velho e influente, Mário segue um caminho totalmente diferente. Ele responde à sua própria pergunta e detalha as suas diversas atividades, examina a relação entre vida e arte e critica severamente o modo pelo qual Drummond a encara, relata uma experiência dionisíaca que o surpreendeu no carnaval carioca e, por fim, com uma franqueza quase desconcertante, faz um balanço da sua obra estética e a diminui frente a um objetivo maior, para cuja consecução convoca o jovem modernista mineiro: a construção da nacionalidade.

O que mais importa aqui, ainda que alguns desses temas específicos venham a ser brevemente retomados, é a atmosfera da intimidade, urgência e intensidade que envolve esta primeira carta enviada a Drummond. É como se Mário fizesse questão de deixar bem claro, desde o começo, que ele iria sempre se expressar de maneira absolutamente autêntica, leal e transparente, descartando inteiramente qualquer compromisso com o "bom-tom" e a sua retórica. Não é que exista uma associação automática entre eloquência e falsidade, como se tentou acreditar desde o romantismo oitocentista: o que está em jogo, ao contrário, é a indicação de dois registros distintos e paralelos onde parece estar situada a nossa concepção moderna de verdade.

No primeiro deles, habitualmente vinculado à ideia de sinceridade, lidase com uma acepção eminentemente clássica do conceito de verdade, na qual o que mais interessa é o estabelecimento de uma espécie de compatibilidade entre o que se diz e o que se sente, entre a aparência e o ser. Só que essa compatibilidade deve ser instituída em prol do que se diz - e faz - na esfera pública, cuja sociabilidade, em suas distintas versões - aristocrática, plebeia ou burguesa -, tornar-se-ia evidentemente mais confiável quanto mais estivesse saturada de sinceridade. O recurso à retórica, então, seria perfeitamente legítimo, inclusive porque, fundada na verdade, ela seria capaz, em troca, de trajá-la da forma mais adequada e elegante, adornando-a com as "flores da eloquência" para que ela tivesse melhores condições de combater pela imposição da virtude.

Já no que diz respeito ao segundo registro da ideia de verdade, que pode ser denominado de autenticidade, mantém-se aquela obsessão com a congruência entre o ser e a aparência, entre a sensação íntima e a sua feição mundana. Neste caso, porém, a ênfase é trocada, ou seja, privilegia-se acima de tudo a expressão dos sentimentos mais originais e profundos, os quais, como entidades dotadas de aura, podem, com o calor que os caracteriza, tanto queimar e destruir a vida social quanto elevá-la as alturas do sublime (cf. BENJAMIN 1985). ${ }^{3}$

${ }^{3}$ A oposição entre sinceridade e autenticidade é analisada por Trilling (1971) e Gonçalves (1996). 
E é justamente a autenticidade que parece orientar, como foi sugerido, o esforço de Mário em impor uma forma à sua subjetividade na correspondência com Drummond. Desdenhando os limites da retórica epistolar, ele sublinha a importância das dimensões mais singulares e enfáticas da sua personalidade, assumindo inclusive uma posição de nítida superioridade em relação ao seu interlocutor.

Claro, Drummond era um desconhecido e incipiente poeta de província enquanto Mário fazia parte do "núcleo duro" do modernismo paulista, havia participado da Semana de Arte Moderna e tinha acabado de visitar Minas juntamente com outros ilustres intelectuais. O que mais me impressiona, contudo, são os argumentos que ele mobiliza no afã de consolidar aquela posição. Com efeito, desde o início da primeira carta endereçada a Drummond, Mário procura demonstrar a sua enorme capacidade de desempenhar simultaneamente as mais diferentes atividades:

[...] escrever dísticos estrambóticos e divertidos prum baile futurista que vai haver na alta roda daqui (a que não pertenço, aliás). Escolher vestidos extravagantes mas bonitos pra mulher dum amigo que vai ao tal baile. E escrever uma conferência sem valor mas que divirta pra uma festa que damos, o pianista Sousa Lima e eu, no Automóvel Clube, sexta-feira que vem. São as minhas grandes preocupações do momento (FROTA 2002, p. 46).

Sempre Ihes conferindo a mesma importância:

Serão desprezíveis pra qualquer idiota antiquado, aguado e simbolista. Pra mim são tão importantes como escrever um romance ou sofrer uma recusa de amor. Tudo está em gostar da vida e saber vivê-la. Só há um jeito feliz de viver a vida: é ter espírito religioso. Explico melhor: não se trata de ter espírito católico ou budista, trata-se de ter espírito religioso pra com a vida, isto é, viver com religião a vida. Eu sempre gostei muito de viver, de maneira que nenhuma manifestação da vida me é indiferente (FROTA 2002, p. 46).

Como se percebe, "viver com religião a vida" implica experimentá-la em todas as suas manifestações e, sobretudo, em sua máxima intensidade, e é exatamente desta perspectiva, fundamentalmente autêntica, que Mário vai interpelar Drummond e os outros jovens poetas de Minas Gerais - e do Brasil: livrescos, deslumbrados pela sua vocação, em suma, requintados "homens de gabinete", eles não conseguem "gosta[r] de verdade da vida. Como não atinaram com o verdadeiro jeito de gostar da vida, cansam-se, ficam tristes ou então fingem alegria o que ainda é mais idiota do que ser sinceramente triste" (FROTA 2002, p. 47-48). Não se trata de desqualificar essa vocação: "que diabo! estudar é bom e eu também estudo. Mas depois do estudo do livro e do gozo do livro, ou antes vem o estudo e gozo da ação corporal" (FROTA 2002, p. 48), mas de batalhar para que ela não envolva um afastamento definitivo do colorido e do calor encontráveis quer nos sentimentos mais íntimos quer no som e na fúria que costumam atravessar o mundo da experiência. 
Na verdade, a impressão que Mário transmite é a de que esta hipertrofia da racionalidade foi a maior responsável pela distância que parece separar o estilo pessoal desses poetas iniciantes daquela que aparentemente se converteu em uma das características mais salientes da sua identidade: um vigoroso, inusitado e permanentemente reafirmado espírito de sacrifício. Sacrifício, neste contexto, tem um significado bastante preciso: o abandono da sua obra poética, das suas pretensões em se constituir como um grande artista em função da ênfase, da veemência típica daquela relação "religiosa" com a vida.

Retornamos assim, por intermédio da noção de sacrifício, ao já discutido argumento que aproxima a intensidade ao conceito de autenticidade. Para não permanecermos cativos da circularidade dessa reflexão, a melhor alternativa talvez seja a de recorrer a outra carta de Mário, de 23 de agosto de 1925, na qual ele vai se deter para meditar acerca do sentido que pode ser encontrado na ideia de felicidade.

Agora, "ser feliz", nesta carta, importa antes de mais nada em "ser", desde que se compreenda que

ser é ser em relação: ser em relação à humanidade (e nisso está incluído necessariamente a nacionalidade que é fatalmente manifestação de humanidade...), ser em relação à família, ser em relação a si mesmo (FROTA 2002, p. 140).

Por conseguinte, não é à toa que naquela sua primeira carta, de 1924, Mário associa de forma imediata o sacrifício da sua vocação estética à urgente necessidade de se comprometer com a tarefa de conferir uma alma "pra este monstro mole e indeciso que ainda é o Brasil" (FROTA 2002, p. 50). E que fique bem claro: "eu não amo o Brasil espiritualmente mais que a França ou a Cochinchina. Mas é no Brasil que me acontece viver" (FROTA 2002, p. 51).

A preocupação com a construção da nacionalidade, portanto, não surge como uma expressão - romântica - de uma força inexorável e telúrica, mas, ao contrário, como um caminho capaz de permitir que Mário, através do seu vínculo com o Brasil, reúna condições para "ser em relação à humanidade" e, em decorrência desse movimento, alcançar um dos patamares onde parece estar alojada aquela sensação de felicidade.

Modelando sua identidade dessa forma, Mário parece encontrar em Drummond - no Drummond de 1924-1925, é lógico - o oponente ideal: "homem de gabinete" por excelência, decadente e meio niilista, isto é, discípulo de Anatole France, ${ }^{4}$ que não hesita em confessar que "ach[a] o Brasil infecto... o Brasil não tem atmosfera mental; não tem literatura; não tem arte; tem apenas uns políticos muito vagabundos e razoavelmente imbecis ou velhacos" (FROTA 2002, p. 56-57). Dessa maneira, não chega a ser uma surpresa quando ele afirma 
Não s[er] suficientemente brasileiro. Mas, às vezes, me pergunto se vale a pena sê-lo. Pessoalmente, acho lastimável essa história de nascer entre paisagens incultas e sob céus pouco civilizados... Sou um mal cidadão, confesso. É que nasci em Minas, quando devera nascer (não veja cabotinismo nessa confissão, peço-Ihe!) em Paris. O meio em que vivo me é estranho: sou um exilado (FROTA 2002, p. 56).

O contraste entre os dois amigos, na verdade, pode inclusive ser avaliado de forma ainda mais aguda e radical, pois Drummond não representa apenas o jovem afrancesado e estetizante em conflito com a vitalidade e o nacionalismo postulados por Mário. Com efeito, ele concorda com este último acerca do fato de que chega a ser

indecente continuar a ser francês no Brasil, [o que o obrigaria a] renunciar à única tradição verdadeiramente respeitável para mim, a tradição francesa. Tenho que resignar-me a ser indígena entre os indígenas, sem ilusões... Aí o lado trágico do caso. É um sacrifício a fio [sic], desaprovado pela razão (como todo sacrifício). Confesso-lhe que não encontro no cérebro nenhum raciocínio em apoio à minha atitude. Só o coração me absolve. E isto não basta. Há sempre o caquinho de lógica procurando intrometer-se entre as nossas contradições. Daí as dúvidas, as flutuações do meu espírito, hoje, amanhã e depois d'amanhã (FROTA 2002, p. 59).

Estamos, desse modo, diante de outra versão daquele "monstro mole e indeciso" anteriormente associado ao Brasil, o que somente consegue acentuar a oposição que distancia os dois missivistas. Afinal, se recordarmos que a indecisão é parente próxima da inconstância e que esta, na chave da economia clássica dos humores (cf. PIGEAUD 2009), define-se como uma das figuras centrais do temperamento melancólico, torna-se perfeitamente razoável aproximar o perfil ostentado por Mário do mais enérgico caráter daquela economia, o sanguíneo. Precocemente envelhecido, frio e seco como os "filhos de Saturno", Drummond se comporta como o simétrico inverso da personalidade fervorosa, essencialmente jovem, encarnada por Mário naquele momento.

Muito bem: chegando a este ponto, creio que seja possível atenuar esse cotejo das diferentes concepções de subjetividade embutidas na correspondência trocada entre Mário e Drummond. O leitor, a propósito, não precisa se preocupar com Drummond: ele termina por se curar ou ao menos melhorar bastante dos males que, segundo Mário, costumavam afligi-lo, ainda que, para tanto, a discussão entre eles devesse se estender por muitos anos e cartas, abrangendo sucessivamente as outras dimensões daquele ideal de conexão e de compromisso que parece se confundir com a própria noção de felicidade.

É necessário, entretanto, aprofundar a investigação sobre a maneira pela qual Mário elabora a sua identidade pessoal, indagando inclusive se as questões já levantadas podem se converter em uma base segura para que se possa prosseguir com a argumentação. Acredito fundamentalmente que sim, embora também imagine que seja indispensável uma melhor qualificação dessa personalidade forte e sanguínea que parece caracterizar o nosso autor, até porque, se recorrermos a outro corpus documental, a correspondência trocada 
com Manuel Bandeira (2000), poderemos surpreender aí, em uma carta de fevereiro de 1923, uma breve passagem que, se não contradiz inteiramente o que acabou de ser dito, no mínimo introduz uma série de nuances e fissuras nessa imagem que Mário faz de si mesmo:

Eu, diretor (ex, porque já chegou o homem que substituía) do Conservatório, crítico gritador, homem corajoso, forte... Pura máscara! Puro Carnaval! No fundo sou uma criança. Infantil. Titubeio. Duvido. Se não tivesse raiva de mim mesmo, creio que choraria (FROTA 2002, p. 85).

Mário como uma criança grande, cheio de dúvidas e titubeios, no limite do choro? Como se pode enfrentar esse suposto paradoxo? Apelando, creio eu, para duas categorias que aparecem repetidamente na própria correspondência com Drummond: as noções de amizade e felicidade, já mencionadas em outro contexto, mas que podem agora permitir uma revisão e um aprofundamento do que se discutiu até o instante.

No que diz respeito à questão da amizade, vale a pena assinalar de imediato que, com toda a autoridade e a energia que o definem, Mário dá a impressão de jamais aceitar o isolamento típico dos líderes e dos gênios. É como se a sua rica e complexa personalidade, precisamente em função da singularidade que a distinguia, se apresentasse sempre de maneira unilateral, necessitando continuamente da crítica - dura, mas construtiva - dos amigos para combater uma espécie de incompletude essencial, o que criaria condições para que ela pudesse se aprimorar e atingir um desenvolvimento que, se dependesse apenas da sua pura e simples interioridade, nunca seria alcançado.

Três breves citações, todas extraídas da correspondência de Mário com Drummond, talvez possam ajudar a tornar o argumento mais evidente e tangível. A primeira, retirada de uma carta de Drummond - mas de um Drummond já educado, ou melhor, "formado" por Mário -, traz um sucinto comentário às críticas que ele recebia dos "passadistas" mineiros por volta de outubro de 1925:

A grande vantagem desses ataques é obrigar a gente a ficar sempre vigilante, sempre rigoroso consigo mesmo, sem concessões ao aplauso do público barato, enfim sem o desejo de agradar, que é o desejo mais torpe do mundo. Ao passo que com o elogio é o contrário. O elogio embala, faz cócegas, satisfaz... O indivíduo acaba inteiramente sem-vergonha e desvirilizado. Pederastia intelectual, vício abominável (FROTA 2002, p. 146).

A segunda envolve um relato feito por Mário, também em 1925, de uma reunião noturna na casa de dona Olívia Guedes Penteado, onde se passa o seguinte:

Foi pensando em você, no Manuel, mais uns dois talvez, que eu pude outro dia gritar bem alto numa reunião na casa de dona Olívia que se os outros não tinham dessas amizades livres de qualquer compromisso de elogio mútuo, amizade pura e livre, eu tinha! Me acreditaram porque eu senti que os meus olhos estavam diferentes no momento. Mas eu tive orgulho da minha felicidade (FROTA 2002, p. 114). 
O terceiro trecho a ser mencionado - provavelmente o mais significativo de todos -, conclui esta mesma carta e lida com a questão de modo eminentemente afirmativo:

Drummond, quando a gente se liga assim numa amizade verdadeira tão bonita, é gostoso ficar junto do amigo, largado, inteirinho nu. As almas são árvores. De vez em quando uma folha da minha vai avoando poisar [sic] nas raízes da de você. Que sirva de adubo generoso. Com as folhas da sua, Ihe garanto que cresço também (FROTA 2002, p. 118).

Estamos, como se pode perceber, no mais legítimo terreno do idealismo alemão, marcado pela ideia de Bildung, isto é, de um projeto de formação, de aperfeiçoamento da personalidade que exige a intervenção de algo externo e objetivo que, agindo como se fosse um desafio lançado à vida interior, força a subjetividade a se transformar para enfrentá-lo, fazendo com que, por essa rota, ela termine por alcançar um estágio superior, mais cultivado de si mesma. ${ }^{5}$

Aliás, as recorrentes alusões às doenças e às dores físicas que povoam a correspondência de Mário tanto com Drummond quanto com Bandeira talvez consigam ser mais bem compreendidas se forem aproximadas desse mesmo ideal de Bildung. É preciso observar, antes de seguir adiante, que essas alusões são tão abundantes que o próprio Drummond - farmacêutico por formação, não nos esqueçamos - monta um apêndice à edição das cartas que recebe de Mário, no qual exibe inúmeras passagens que confirmam essa aparente obsessão do seu amigo e interlocutor, e que se intitula "Não sou um sujeito fisicamente são" (FROTA 2002, p. 561).

Vejamos só uma delas:

Fiz uma operação que não tinha importância porém o certo é que depois de seis dias de dores cruciantes, que dores meu Deus, que só sossegavam com morfina, inda vieram uma cicatrização dolorosíssima, uma fraqueza de morte por causa de seis dias de quase jejum absoluto e este desespero louco de saber a vida existindo e sem viver, sem trabalhar, meu Deus! Sem trabalhar! Ontem de noite confesso que chorei (FROTA 2002, p. 563).

O que mais chama a atenção nessa e nas outras citações, contudo, é o fato de que, quando lidas no contexto em que foram escritas, elas ganham um sentido particular e bem mais discreto, pois referem-se a doenças que sempre parecem atacar Mário de fora para dentro, como se fossem acidentes - externos e objetivos - que seguramente o atrapalham mas que, pelo menos nesta quadra da sua vida, nunca são capazes de impedir a sua reação. Ele exibe aqui uma postura bem diversa daquela adotada por Manuel Bandeira, que transmite a sensação de haver transformado a doença - sua tuberculose - em uma das bases da sua personalidade: "eu era muito mansamente e muito doloridamente

\footnotetext{
${ }^{5}$ A discussão sobre o conceito de Bildung pode ser encontrada no livro de Dumont (1991). No que se refere à possibilidade de analisar ao menos uma parte da produção intelectual de Mário à luz deste conceito, deve-se examinar o primeiro capítulo de Naves (1998).
} 
tísico. Hoje sou ironicamente, sarcasticamente tísico" (2000, p. 97), chegando ao ponto de pautar todo o seu futuro em função dela:

Perguntas pelos meus poemas e pelos meus projetos. Não tem projetos quem vive como eu ao Deus dará do amanhã. Sabes o que me disse o médico de Clavadel quando me ascultou pela última vez em 1914? Que eu tinha lesões teoricamente incompatíveis com a vida! O meu organismo acabou espontaneamente vacinado contra a infecção tuberculosa, mas fiquei um inválido. Sou incapaz de um esforço seguido... Como eu teria vontade de fazer prosa, de escrever dois ou três romances! Isto então é completamente impossível (FROTA 2000, p. 94; grifo no original).

Mário, por sua vez, não parece converter os males físicos em uma condição, por mais que fale incessantemente deles. Assim, em outra carta enviada a Bandeira, no meio de uma discussão sobre algumas sugestões para que alterasse alguns dos seus poemas, dá-se o seguinte:

Vou também tirar a metáfora 'Favorita do harém dos meus desejos', não sei se basta cortar; não me lembro do poema que há dois meses não leio. Quanto àquela parte inicial, talvez tenhas também razão. Quase que estou certo que a razão é tua, não sei, preciso pensar. E ainda não me dei ao trabalho de pensar. Logo depois de receber tua carta, fiquei doente. Um abscesso na pálpebra do olho esquerdo. E desenvolvido para a parte interior. Meu médico, meu especialista quiseram rasgá-lo... oh! vida de Proust que tenho suportado! Infelizmente é só vida.

$\mathrm{E}$ tu? que fazes? Manda-me alguns versos teus. Não publicas algum livro proximamente? fala-me de teus projetos. Se Klaxon sair mais uma vez, permitirás a colocação do poema 'Rua do Sabão' nela? Sim. Obrigado (FROTA 2000, p. 92).

Como se pode perceber, a questão da doença surge inopinadamente, sem qualquer relação mais significativa com o assunto que está sendo discutido, e, assim como vem - de fora da vida e do texto -, logo desaparece, sem deixar maiores vestígios. ${ }^{6}$

Dessa forma, embora lamente o provável aborrecimento do leitor, acredito que valha a pena enfatizar o ponto: tanto as relações de amizade quanto a experiência com a doença dão a impressão de estar associadas com aquele processo de aprimoramento da subjetividade conectado ao ideal de Bildung. De fato, se ser é sempre ser em relação, ser em relação a si mesmo parece passar pela inevitável e exigente mediação das críticas - inerentes à "verdadeira" amizade - e das dores que acompanham os males físicos. Ambas trazem embaraços e dificuldades objetivas que, por isso mesmo, são capazes de provocar uma reação afirmativa em Mário, dando-Ihe condições de tentar enfrentar aquelas ameaças de imaturidade e de fragilidade, mesmo

\footnotetext{
${ }^{6}$ É importante observar que existe também outra menção a doença na correspondência de Mário com Drummond, desta feita de maneira bem mais focada e precisa, menção que permite inclusive aproximá-lo daquele temperamento melancólico já vinculado a Drummond. Trata-se de uma neurastenia que o acometeu em 1913, por ocasião da morte - acidental - do irmão mais novo e num contexto de enorme desgaste físico e mental, como nos mostra a análise recente de Wegner (2012). No entanto, de modo compatível com o que está sendo sugerido neste texto, tal neurastenia é sempre recordada como um problema, não exatamente superado, mas inteiramente controlado, e controlado justamente pelo fortalecimento da sua vontade e da sua devoção ao trabalho.
} 
sem qualquer perspectiva de superá-las totalmente, e conduzi-lo ao que poderíamos chamar de felicidade possível.

Chegamos, então, a outra categoria que havia sido mobilizada, juntamente com as relações de amizade, para tentar explicar a forma pela qual se dava a convivência de uma identidade tão forte como a de Mário com aquela sensação de desamparo e abandono típicas da infância e dos enfermos. Ora, uma simples consulta aos últimos parágrafos, nos quais a concepção de amizade praticada pelo nosso autor confina com os malefícios da doença, pode eventualmente nos auxiliar a perceber que lidamos aqui com uma acepção particular do conceito de felicidade, na qual ele jamais se separa do sentimento de dor:

A própria dor é uma felicidade. Pra felicidade inconsciente por assim dizer física do homem comum qualquer temor qualquer dor é empecilho. Pra mim não porque pela minha sensibilidade exagerada, pela qual eu conheço por demais, a dor principia, a dor se verifica, a dor me faz sofrer, a dor acaba a dor permanece na sua ação benéfica histórica moral, a dor é um dado do conhecimento, a dor é uma compreensão normalizante da vida, a própria dor é uma felicidade (FROTA 2002, p. 129; grifo do original).

Nesse sentido, longe de se estabelecer em um terreno utópico, no futuro ou no além, em um lugar ao abrigo do infortúnio e da tragédia, a definição de felicidade empregada por Mário parece receber um significado provisório e extremamente arriscado (cf. MARQUARD 2006). Entretanto, é exatamente por causa dessa opção por um ambiente marcado pela precariedade e por uma espécie de incompletude "essencial" que tanto a amizade quanto a dor e a felicidade, tal como definidas na correspondência em pauta, mostram-se capazes de gerar uma energia que tenha forças para sustentar e desenvolver aquele sujeito intenso e sanguíneo examinado ao longo destas páginas. Não se trata de desconhecer nem muito menos de erradicar as fendas e as fissuras que o ameaçam, mas de converter o perigo em oportunidade, transformando as dificuldades em alento para que ele tenha chance de procurar se aperfeiçoar e tornar-se ainda mais forte. O que não mata, engorda!

Por fim, cabe observar que, se o que foi dito até agora for minimamente verdadeiro, ainda resta a necessidade de explicar melhor a escolha da correspondência como uma forma privilegiada para se entrar em contato com o mundo. O próprio fato de Mário reconhecer no final da sua primeira carta a Drummond que sofria de "gigantismo epistolar" - e ele se referia apenas à extensão das suas missivas, não à absurda quantidade que estava disposto a escrever - este próprio fato, repito, se por um lado torna possível certa naturalização da preferência concedida à correspondência, por outro, também revela uma espécie de estranheza, um resto de constrangimento por se valer de forma tão excessiva desse recurso.

Na verdade, Mário utiliza-se largamente de todos os meios à sua disposição, como crônicas jornalísticas, palestras e entrevistas, para disseminar os seus argumentos acerca da arte moderna e da alma nacional. Entretanto, todos sabemos sobejamente, dedica à troca de cartas um cuidado especial, constituindo um acervo que, ainda hoje, está longe de ser completamente aquilatado. 
Por qual razão? Deve-se repisar, antes de mais nada, que as cartas que ele escreve, bem distintas de qualquer modelo retórico, são textos impregnados de subjetividade: íntimas e singulares, cada uma delas dá a impressão de conter um pequeno pedaço do espírito de quem as redigiu, implicando não uma representação sistemática e planejada da sua personalidade, mas a presença original, autêntica e portanto aurática - no sentido conferido por W. Benjamin (1985) a este conceito - do próprio Mário.7

Interpretada desta maneira, a gigantesca correspondência de Mário parece se constituir em um mecanismo capaz de conferir eficácia àquele sacrifício da obra poética acima mencionado. Afinal, por maior que seja o volume das cartas e o número de seus interlocutores, cada uma delas, definida como um fragmento real, vivo e intenso, da subjetividade do seu autor, exige ser levada a sério e no mínimo respondida, sob pena de que aquela voz distante, frágil e precária - ainda que autêntica -, enviada como uma dádiva, possa vir a desaparecer. Contudo, um movimento como este, que associa a dádiva à troca e a uma promessa de aliança e de felicidade, está longe de ser automático: cartas se extraviam pelas mais variadas razões, podem com frequência ser mal interpretadas, refutadas ou, pior ainda, simplesmente desconsideradas, deixadas de lado - até fechadas -, em uma nítida demonstração de desprezo que pode muito facilmente degenerar em inimizade e conflito.

Assim, no espírito mesmo do trabalho clássico de Marcel Mauss (2003) sobre a noção de dádiva, podemos surpreender uma espécie de ambiguidade fundamental que parece assolar a troca de correspondência no Ocidente moderno. Por um lado, precisamente em função daquela capacidade de manter viva e próxima a personalidade e, sobretudo, a presença de alguém que pode estar bem distante, as cartas definem-se como um meio bastante adequado para tecer e ampliar vínculos de amizade; por outro, elas transmitem a sensação de confinar em um universo caracterizado pela incerteza, pelo risco e pela imprecisão, transitando com alguma facilidade entre o afeto e o insulto, a convergência absoluta e a mais completa - e por vezes inesperada - dissidência.

Autenticidade, amizade, crítica, dor e felicidade: a percepção que se tem é a de que existe uma espécie de afinidade eletiva entre a troca de correspondência e algumas das formas pelas quais Mário encaminha e cultiva a própria personalidade, o que talvez possa apontar para a construção de uma hipótese, mais consistente, que tenha condições de contribuir para que se amplie a interpretação da sua fascinante e complexa paixão epistolar.

\section{Referências bibliográficas}

BENJAMIN, Walter. A obra de arte na era de sua reprodutibilidade técnica. In: . Magia e técnica, arte e política. São Paulo: Brasiliense, 1985.

CAMPOS, Regina Salgado. A latinidade na América do Sul: Anatole France e Paul Adam. In. PERRONE-MOISÉS, Leyla (org.). Do positivismo à

\footnotetext{
${ }^{7}$ A noção de presença aqui referida remete ao texto de Gumbrecht (2010).
} 
desconstrução: ideias francesas na América. São Paulo: Edusp, 2004.

FROTA, Lélia Coelho (org.). Carlos e Mário: Correspondência entre Carlos Drummond de Andrade - inédita - e Mário de Andrade: 1924-1945. Rio de Janeiro: Bem-Te-Vi, 2002.

CHARTIER, Roger (org.). La correspondance: les usages de la lettre au XIX siècle. Paris: Fayard, 1991.

MORAES, Marcos Antonio de (org.).Correspondência Mário de Andrade \& Manuel Bandeira. São Paulo: Edusp/Instituto de Estudos Brasileiros, 2000.

DUMONT, Louis. L'ideologie allemande. Paris, Gallimard, 1991.

GONÇALVES, José Reginaldo. A retórica da perda: os discursos do patrimônio cultural no Brasil. Rio de Janeiro: Editora UFRJ/IPHAN, 1996.

GUMBRECHT, Hans Ulrich. Produção de presença. Rio de Janeiro: Contraponto/ Editora PUC-Rio, 2010.

KARSENTI, Bruno. Marcel Mauss. Le fait social total. Paris: PUF, 1994. MAUSS, Marcel. Ensaio sobre a dádiva. In: Sociologia e Antropologia.

São Paulo: Cosac \& Naify, 2003. ; HUBERT, Henry. Sobre o sacrifício. São Paulo: Cosac \& Naify, 2005. MARQUARD, Odo. Felicidad en la infelicidad. Buenos Aires: Katz, 2006. MICELI, Sergio. Poder, sexo e letras na República Velha. São Paulo: Perspectiva, 1977.

Mário de Andrade: A invenção do moderno intelectual brasileiro. In. BOTELHO, André; SCHWARCZ, Lilia (orgs.). Um enigma chamado Brasil. São Paulo: Companhia das Letras, 2009.

MORAES, Marcos Antonio. Orgulho de jamais aconselhar: a epistolografia de Mário de Andrade. São Paulo, Edusp/Fapesp, 2007.

NAVES, Santuza Cambraia. O violão azul: modernismo e música popular. Rio de Janeiro: Ed. FGV, 1998.

PIGEAUD, Jackie. Metáfora e melancolia: ensaios médico-filosóficos. Rio de Janeiro: Ed. PUC-Rio/Contraponto, 2009.

TRILLING, Lionel. Sincerity and Authenticity. Cambridge: Harvard University Press, 1971.

WEGNER, Robert. A doença nervosa de Mário de Andrade. In: XXXVI ENCONTRO ANUAL DA ANPOCS, 2012, Águas de Lindoia, Anais.... 2012. 